\title{
A MOBILIDADE CELULAR ${ }^{1}$
}

RESUMO: O termo mobilidade tem aparecido de maneira cada vez mais frequente em nosso vocabulário. Utilizado com diversos sentidos, tornou-se uma qualidade bastante festejada, descjada, positiva, em grande parte por conta de sua associação com as tecnologias móveis de comunicação, em especial, a tecnologia celular. Pois bem, o artigo que se apresenta pretende fazer ver quais são as formas de mobilidade produzidas por essa tecnologia explorando sua lógica de funcionamento $\mathrm{c}$ sua linha evolutiva. Trata-se, portanto, de explorar as tecnicidades da rede celular de comunicação e verificar as formas de mobilidade que se manifestam em seus terminais móveis (os telefones celulares): enquanto objetos que articulam comunicação e movimento, e que se encontram num processo de constante mutação e adaptação, convergindo formas e funções.

PALAVRAS-CHAVE: mobilidade, tecnologia, comunicação, telefonia celular, convergência.

The device is well named. In England and many parts of the world, it is called a mobile phone, but "cellphone" is better. Because it not only travels, like organic cells do, but, also like cells, it can generate new communities, new

\footnotetext{
${ }^{1} \mathrm{O}$ presente artigo bascia scus argumentos na dissertação de mestrado defendida pelo autor no departamento de sociologia do IFCH/Unicamp, sob o título: " $\Lambda$ mobilidade como artigo de consumo: apontamento sobre as relações com o aparelho cclular". Disponivel em: http://libdigi.unicamp.br/document/?code $=\mathrm{vtl}$ s000444257.

${ }^{2}$ Mestre em sociologia e membro do grupo de pesquisas CleMe (Conhecimento, T'ecnologia e Mercado) da Unicamp.
} 
possibilities and relationships, wherever it happens to be. The cellphone in other words, is not only mobile, but generative, creative. And the word "cell" works in another way as a description of what a cellphone does. For it not opens up possibilities, but pressures us to always be in touch. This aspect of the cellphone thus can imprison us in a cell of omni-accessibility. (LEVINSON, 2004, p.xiii)

Logo no prefácio de seu livro, o professor Paul Levinson (2004) sugere que cellphone é a melhor denominação para o aparelho que, hoje, a maioria das pessoas leva junto ao corpo. Como se sabe, tal nomeação advém do modo de funcionamento da tecnologia celular de comunicação, cuja rede divide o território de cobertura em células hexagonais. Levinson deixa em segundo plano a raiz técnica do nome, e joga com os significados da palavra cell. A tática é interessante na medida em que o paralelo de significados torna inteligíveis algumas das propriedades desta relação entre homem e objeto técnico.

No entanto, ao contrário do que Levinson gostaria, o nome cellphone perde cada vez mais espaço para a palavra mobile. A despeito de poder ser chamado localmente de telemóvel, le portable ou keitai, é fato que o aparelho celular cada vez mais é referido nos livros e eventos internacionais apenas por mobile, suprimindo a palavra phone da nomeação britânica original. Pressupondo que isso não seja mero acaso, pode-se dizer que a mobilidade prevalece como qualidade que melhor define o objeto. Mas afinal, o que é mobilidade? Ou, melhor ainda, quais formas de mobilidade são produzidas pela telefonia celular?

Pois bem, a manifestação mais evidente da mobilidade celular ć a capacidade de articular comunicação e movimento. O celular é um terminal portátil por meio do qual é possível acessar um ambiente comunicativo que ultrapassa o horizonte sensível. Através dele é possivel trafegar simultaneamente pelo espaço real e virtual desde que você se restrinja ao território de cobertura da rede. No limite, ser mobile é ter sempre a capacidade de interferir em dois espaços distintos: o entorno imediato e o ciberespaço. 


\section{PRINCÍPIO DA REDE CELULAR}

A articulação entre comunicação e movimento não é algo absolutamente novo. Numa espécie de pré-história da telefonia celular, a associação entre automóveis e rádios comunicadores deu ensejo ao surgimento da radiotelefonia pouco antes da metade do século XX, nos EUA. A estrutura da rede era relativamente simples: uma torre central servia de interface, via sinal de rádio, entre a estação telefônica da cidade e os radiocomunicadores instalados nos veículos. No entanto, de pronto esse sistema apresentou suas limitações. Já em 1947 a cidade de Nova York contava com 730 usuários habilitados e mais de dois mil com seu nome numa lista de espera. Havia apenas 12 canais disponíveis para os 730 usuários, isso quer dizer que o sistema suportava apenas 12 conversações simultâneas (Cf. AGAR, 2003).

A limitação de canais ocorria por conta da escassez do espectro cletromagnético, que naquela altura já se encontrava congestionado. Explico: cada canal é formado por duas frequências de onda de rádio, uma para emissão e outra para recepção de sinais. Essa troca de sinais é feita entre o aparelho de radiotelefonia instalado no automóvel, e a antena central da cidade (ligada à rede de telefonia fixa), portanto, ć o que possibilita a conversação simultânea em duas vias. Acontece que, sendo o espectro eletromagnético de ondas de rádio uma "matéria-prima" limitada, e servindo a diversos usos, já nos anos trinta foi criada a Comissão Federal de Telecomunicações (FCC, em inglês), nos EUA, para regular seu uso e autorizar as empresas e demais entidades a ocupar espaços determinados do

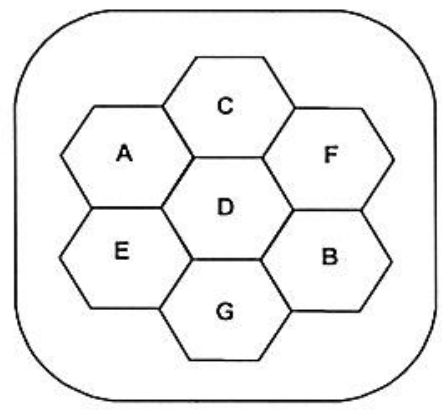
espectro. Portanto, cada empresa podia utilizar um número limitado de frequências. Noutras palavras, principiava o problema técnico que acabaria por gerar a tecnologia de comunicação celular: como ampliar os canais de comunicação sem rarear o espectro de ondas?

O que se fez foi reutilizar as frequências de onda, dividindo o território de cobertura 
da rede telefônica em células hexagonais, cada qual com um conjunto de frequências distintas da célula vizinha, diminuindo assim a possibilidade de interferência e ampliando a capacidade de expansão da rede sem exigir mais espaço dentro do espectro.

Suponhamos que uma determinada empresa de telefonia móvel tenha recebido o direito de utilizar um "pedaço" (banda) do espectro, e a partir daí tenha optado por utilizar um esquema de reuso de frequências em que a banda disponível é dividida em 7 grupos (de $A$ até $G$ ). Então, cada um desses grupos irá corresponder à cobertura de uma área territorial de forma hexagonal, a que chamamos de célula. Cada célula é disposta de maneira que as que estão no scu entorno imediato, ou que lhe são adjacentes, reúnam um grupo de frequências distinto $\mathrm{cm}$ relação ao scu próprio grupo. Esse padrão de distribuição, ao ser replicado, garante que determinado território possa ser inteiramente coberto, utilizando sempre os mesmos sete grupos de frequência de onda. Antes da divisão do espectro c do território, não seria possível ampliar os limites territoriais da rede de maneira ilimitada, já que duas ou mais antenas quando operam com as mesmas frequências de onda interferem no sinal uma da outra.

O sistema de reutilização de ondas foi importante também para fazer com que o aparelho de telefone saltasse do automóvel para o bolso. Com a divisão de um determinado espaço urbano em células e a consequente multiplicação das antenas (ou Estações Rádio Base - ERB), tanto os aparelhos de telefone quanto as próprias antenas passam a funcionar com transmissões de baixa potência, para que a emissão do sinal não

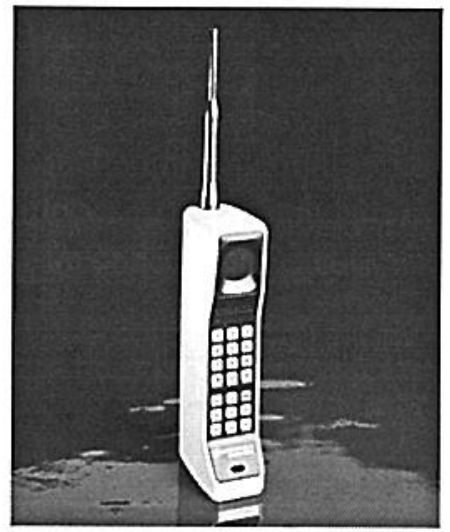

Motorola 8000. O aparelho que media mais de trinta centimetros e pesava quase um quilo, foi o primeiro telefone móvel a ser comercializado em versão portátil. 
ultrapasse em muito os limites espaciais da própria célula. Menor potência resulta em menor gasto de energia, o que fez com que as baterias pudessem ter seu tamanho reduzido a ponto de tornar portáteis os aparclhos telefônicos que até então podiam transitar apenas dentro de veículos. Claro que todo o avanço na microeletrônica, produzindo componentes cada vez menores, também foi decisivo para conferir portabilidade ao celular.

Em suma, portanto, esse é o princípio de funcionamento da rede celular de comunicação: cada célula hexagonal corresponde à cobertura de uma torre munida de um receptor e transmissor de ondas, que se comunica com os aparelhos de telefone que estão em seu raio de ação; tais aparelhos, ao transitarem de uma célula à outra, dentro de um mesmo espaço urbano, por exemplo, mudam automaticamente de frequência, sem que a ligação seja interrompida. Assim, embora as células vizinhas estejam sempre funcionando em frequências distintas, há um número finito de frequências que se repete dentro do espaço de cobertura da rede, inibindo interferências e possibilitando sua expansão. Tais princípios básicos se mantêm até hoje. Mas, as tecnologias de telefonia celular vêm sofrendo alterações desde o início de sua implementação. De lá para cá, foram desenvolvidos diversos tipos de padrões tecnológicos no mundo todo, que até aqui se enquadram basicamente em três categorias evolutivas: primeira, segunda e terceira gerações.

As tecnologias $1 \mathrm{G}$, ou de primeira geração, correspondem à transmissão analógica de dados, cujo funcionamento básico acabamos de descrever. $\mathrm{O}$ padrão mais utilizado desta tecnologia foi chamando AMPS (Serviço Avançado de Telefonia Móvel) que entrou em funcionamento nos EUA em 1983 e foi desenvolvido pelos laboratórios Bell, da AT\&T. O AMPS é uma tecnologia que utiliza o múltiplo acesso por divisão de frequência (FDMA, cm inglês), i.c., permite o acesso de múltiplas chamadas em uma mesma célula dividindo a banda desta célula em diferentes frequências que se destinam, em dupla, a cada uma das chamadas. Cada canal, ou dupla de frequências, é acionado quando se faz uma chamada telefônica de (ou para) algum terminal móvel que esteja na região satisfeita pela rede. Acontece que, exatamente como sua predecessora (a radiotelefonia), esta tecnologia esbarra no limite de conversações imposto pela escassez espectral. Sendo assim, mesmo com o 
ganho da divisão do território em células, a demanda crescente por serviços de telefonia móvel, principalmente em zonas urbanas de grande densidade demográfica, fez com que o limite do sistema fosse novamente atingido, fato que deu origem às tecnologias de segunda geração $(2 \mathrm{G})$.

Como se vê, a passagem de $1 G$ para $2 G$ deve-se a um dos motivos que levou ao salto entre o sistema de radiotelefonia c o sistema de telefonia celular: o número restrito de canais e, consequentemente, de usuários. Noutras palavras, se a necessidade de dar conta do crescimento da demanda de usuários contribuiu para que o sistema de radiotelefonia instalado no final dos anos $1940 \mathrm{em}$ Nova York (EUA) fosse substituido pela rede celular de comunicação (já na década de 1970), esta última, por sua vez, também atingiu seu limite no final dos anos 1980 quando o telefone já não estava mais preso aos automóveis e ganhara popularidade.

As tecnologias $2 \mathrm{G}$ vieram resolver esse problema e, quando menos, triplicaram a capacidade do sistema em relação às tecnologias $1 \mathrm{G}$. O principal salto da nova tecnologia foi a digitalização do sinal, o que permitiu com que fosse mais facilmente comprimido e manipulado em seu processo de transmissão. Na segunda metade da década de 1980, quatro tecnologias $2 \mathrm{G}$ se desenvolveram em diferentes localidades do mundo, duas delas nos EUA, uma no Japão e outra na Europa. Respectivamente, são: (1) Sistema de Múltiplo Acesso por Divisão de Tempo (TDMA, em inglês); (2) Sistema de Múltiplo Acesso por Divisão de Código (CDMA, em inglês); (3) Sistema Japonês de Comunicação Celular Digital Pessoal (PDC, em inglês); (4) Sistema Global para Comunicações Móveis (GSM, em inglês).

Imagino que o leitor já tenha ouvido falar de ao menos três das quatro siglas acima, ainda que, muito provavelmente, o modo como funcionam the seja um verdadeiro mistério. De fato, o grau de complexidade do funcionamento desses sistemas parece aumentar proporcionalmente à sua capacidade de transmissão de dados. De todo modo, tentaremos desvendar um pouco desse enigma. Para isso, vamos explorar aquele que se tornou o mais popular entre os sistemas $2 \mathrm{G}$. Popularidade esta que, inclusive, fez com que mudasse seu nome de Groupe Spécial Mobile para Global System for Mobile Communications. Originalmente pensado para funcionar apenas na Europa, foi 
num momento oportuno que esse novo sistema de telefonia móvel apareceu: quando o desejo político de maior integração cconômica entre os países do continente aliou-sc à necessidade de superar os sistemas de tecnologia analógica (1G) e fazer frente ao avanço de sistemas do Japão e dos EUA.

Ao iniciar suas operações (em 1992), a tecnologia GSM logrou unificar os padrões curopeus de telefonia móvel e, com isso, viabilizou o roaming entre os países daquele continente, ou seja, tornou possível que um usuário transpusesse fronteiras territoriais entre países do bloco usando o mesmo telefone celular. Em meados da década de 1990, o sistema GSM se difundiu com enorme sucesso por outras partes do mundo, inclusive pelo Brasil.

Com relação a seu funcionamento, a tecnologia GSM guarda a lógica de formação de canais do padrão precedente (FDMA, 1G). Ou seja, também na tecnologia GSM são formados canais a partir da junção de duas frequências: uma para comunicação da antena com o aparelho cclular e outra para o caminho inverso. Como inovação o padrão GSM apresenta a modulação digital e o sistema de aproveitamento do tempo. Em suma, todos os canais de tráfego são divididos em oito porções de tempo (timeslots), de modo que possam suportar oito chamadas simultâneas. Ou seja, na medida em que um determinado canal tenha sido designado a uma chamada telefônica, ela utilizará este canal como via de comunicação entre estação base e estação móvel pelo período estipulado de um timeslot, depois disso, espera sua vez para usar o canal novamente. Portanto, ao contrário do que acontecia nos sistemas $1 \mathrm{G}$, um mesmo canal não é inteiramente alocado em função de uma só chamada. A digitalização do sinal permitiu que a informação de voz fosse comprimida e enviada em espaços intermitentes de tempo, sem que isso interferisse na aparente continuidade da conversa. No limite, ainda que a voz do interlocutor nos pareça contínua quando falamos ao celular, de fato ela cstá sendo enviada de maneira fracionada em pequenos espaços de tempo, a que chamamos timeslots. Para se ter ideia do grau de refinamento da tecnologia, cada timeslot (na tecnologia GSM) possui a duração de 576,9 microssegundos (um microssegundo é o mesmo que $10^{-6}$ segundos).

O salto para a tecnologia $2 \mathrm{G}$ prioritariamente serviu de resposta das operadoras de telefonia ao crescimento da demanda, contudo, como era de 
se esperar, as inovações não se restringiram a isso. A digitalização do sinal permitiu ainda o surgimento de um novo pacote de serviços que deu autonomia ao celular para que não se restringisse mais à fala. É a partir das tecnologias de segunda geração que passamos a contar com uma série de novas funcionalidades, como: identificador de chamadas, conferência, chamada em espera, WAP e, principalmente, o SMS.

O serviço de mensagem curta, conhecido por sua sigla em inglês, SMS, ou ainda, no Brasil, por "torpedo", é uma espécie de acidente que acabou por dar certo. No início da década de 1990, quando o serviço iniciou sua operação, em conjunto com a tecnologia GSM, as empresas de telecomunicação não acreditavam que a tecnologia pudesse atingir o nivel de popularidade a que chegou ${ }^{3}$. Mas, já na metade da década, com o início da comercialização de telefones celulares de tipo pré-pago e a consequente expansão do mercado de celulares para a população jovem e com menos poder aquisitivo, o SMS passou a gozar de enorme popularidade porque economizava créditos, enviando em alguns segundos um recado que provavelmente tomaria minutos numa conversação. Isso implica diferenças com relação à frequência de uso do SMS, que costuma ser mais popular em países periféricos, onde os custos da ligação são proporcionalmente mais altos.

Em resumo, o protocolo SMS confere à tecnologia celular o poder de servir também como interface de comunicação escrita. Sua inesperada popularidade impôs aos fabricantes de aparelho não só o desafio de ampliar a capacidade de visualização $\mathrm{c}$ melhorar a qualidade de cor $\mathrm{c}$ imagem da tela de cristal liquido, como também de tornar mais ergonômico o teclado alfanumérico. Ao mesmo tempo, as operadoras viram a possibilidade de exploração de um novo mercado e passaram a vender todo tipo de serviços informativos via SMS como, por exemplo, boletins metcorológicos ou de

\footnotetext{
${ }^{3}$ Existe uma série de informações desencontradas com relação à paternidade c ao nascimento do SMS, no entanto, quase todos são unânimes $\mathrm{em}$ afirmar que, de início, a indústria não nutria muitas expectativas em relação ao scu uso, difusão, ou como possível fonte de receita. Cf. AGAR (2003:105-111); TAYLOR e VINCEN'T (2005:75-92).
}

Temáticas, Campinas, 18(35/36): 133-148, jan./dez. 2010 
cotação do mercado financeiro. Na verdade, o que se viu foi o surgimento de uma enorme massa de serviços que pretendiam explorar essa nova fatia dentro do mercado de telefonia celular. Trata-se de uma variedade praticamente incontável que inclui o envio de propaganda, a venda de ringtones $\mathrm{e}$ a participação em sorteios, concursos, ou enquêtes.

$\mathrm{Na}$ esteira do SMS e das evoluções que lhe sucederam (tanto nos aparelhos quanto na rede), surgem o EMS (serviço aprimorado de mensagens) e o MMS (serviço de mensagens multimídia). O primeiro ć praticamente uma extensão da mesma estrutura do SMS, com a diferença que comporta o envio de pequenas imagens $\mathrm{c}$ textos formatados. Já o MMS representa um avanço considerável porque inclui a possibilidade de envio de animações, fotos, vídeos e música. Exige, portanto, maior capacidade de transferência de dados e já é um serviço que está atrclado ao avanço para tecnologias intermediárias entre segunda e terceira gerações, comumente chamadas 2,5G.

\section{ACELERAÇÃO DO FLUXO}

Especificamente no que diz respeito aos sistemas GSM, a evolução levou aos padrões GPRS (General Packet Radio Services) e EDGE (Enhanced Data rates for GSM Evolution). Vimos que o sistema GSM aloca uma chamada em cada um dos oito timeslots $\mathrm{cm}$ que são divididos os canais de frequência. Quando alocada em determinado timeslot, todas as informações de voz de uma chamada scrão enviadas por cle até que a conversação termine. Se essa divisão de um mesmo canal em porções de tempo não afeta a fluência de uma conversação, o mesmo não se pode dizer com relação à transferência de um pacote de dados, que se torna um processo moroso e custoso tanto para a operadora quanto para o usuário. Para o primeiro, porque a transferência irá ocupar um canal de tempo da rede por um período demasiadamente longo, enquanto que, para o segundo, a desvantagem se coloca já que a tarifa é cobrada por tempo de conexão. Daí coloca-sc então um novo desafio e prioridade à rede: aumentar sua capacidade de fluxo, ou transmissão de dados. 
Em resposta ao desafio, no modelo GPRS um mesmo pacote de dados enviado ou recebido por uma estação móvel passou a ocupar mais de um timeslot, não de maneira fixa e pré-determinada, mas de acordo com a demanda, ou seja, de acordo com o tamanho do pacote de dados que está sendo enviado ou recebido. É evidente que esta mudança aparentemente pequena vem acompanhada de uma série de outras mudanças, inclusive na infra-estrutura da rede, mas não iremos tratar delas aqui porque fugiríamos ao nosso objetivo que é, nesse momento, demonstrar que o ganho do sistema GPRS em relação ao GSM, no que toca à taxa de transferência de dados, ć da ordem de quase dez vezes mais capacidade de fluxo. Enquanto o modelo GSM pode operar com a taxa máxima de 14,4Kbit/s, o sistema GPRS chega a $171,2 \mathrm{Kbit} / \mathrm{s}$.

Em nova evolução da rede, o padrão EDGE chega como melhoria ao GPRS. Sua introdução representou três vezes mais eficiência na interface aérea, ou seja, novos padrões de modulação do sinal fizeram com que o espaço de um timeslot pudesse transportar três vezes mais informação. $\mathrm{O}$ processo de modulação é aquele em que o sinal original é convertido num formato que seja conveniente à sua transmissão. Um sinal de voz, por exemplo, modula ou informa outro sinal que, este sim, será transmitido pela interface aérea. Em sua recepção, a estação móvel irá demodular o sinal, reproduzindo ou recuperando o sinal de voz original. As diferentes técnicas de modulação são quem decidem se o sinal terá caráter digital ou analógico. No caso específico do padrão EDGE, um novo sistema de modulação permitiu um uso mais eficiente do espectro e dos canais, enviando três vezes mais informação num mesmo canal de tempo, atingindo uma taxa máxima de transmissão na ordem de 473 , $6 \mathrm{kbit} / \mathrm{s}$.

Ao atingir esse nível de desenvolvimento $(2,5 \mathrm{G})$, as operadoras de telefonia passaram a aplicar um novo tipo de tarifação ao usuário, não mais por tempo de chamada, mas por pacote de dados, ou seja, pela quantidade de informações que o aparelho do cliente "baixa" ou "sobe". O consequente barateamento desencadeou uma nova série de serviços e hábitos. A câmera celular, por exemplo, não se limita a uma questão de praticidade, de "possuir dois objetos em um". Na verdade, com a capacidade de transmissão de 
dados por pacote, com boa velocidade, o envio de fotos e imagens tornouse também uma nova forma de utilização comunicativa do celular: visual, imagética. A este respcito, Carole $A$. Rivic̀rc nota que, com a mobile-camera "não falamos mais, não escrevemos mais, nós mostramos" (2006, p.123). A final, é possível imaginar uma infinidade de usos possíveis para um dispositivo que pode produzir e enviar imagens de mancira praticamente instantânea: você está com dúvida na compra de um sapato? Com relação à cor da gravata? Quer saber se o vestido é ou não apropriado à situação? Situações ordinárias de todo tipo - mas que, por algum motivo, parecem extraordinárias para aqueles que acionam o "click" da mobile-camera-resultam no envio de vídeo ou foto e incrementam o fluxo de dados do sistema celular.

Outro serviço que exige eficiência no fluxo de dados, e que é característico desse momento de transição entre segunda e terceira gerações, é a navegação na Internet; algo que impulsionou a venda de novos aparelhos smarlphones e bandlselds - diante de melhores condições para navegação c troca de e-mails. Outra estratégia das operadoras de telefonia foi passar a comercializar dispositivos integráveis a notebooks, para acesso sem fio à Internet. A integração dos aparelhos celulares à "rede mundial de computadores" é uma tendência que se confirma e reforça nos padrões tecnológicos de terceira geração.

Em Junho de 2008, apenas um ano depois do lançamento de sua primeira versão, foi anunciado o lançamento do iPhone 3G. É inquictante, mas não surpreendente, notar que Steve Jobs fez questão de ressaltar, na apresentação do novo gadget, que a versão $3 \mathrm{G}$ do iPhone permite anexar um arquivo de $\mathrm{e}-\mathrm{mail}$ em apenas cinco segundos, enquanto a versão anterior (EDGE) executava a mesma tarefa em dezoito segundos. Diferença de treze segundos essenciais. Mas, afinal de contas, o que representa csse ganho? Antes de tocar a questão, vejamos accrca dos padrões $3 \mathrm{G}$.

A evolução para um protocolo de terceira geração começa a ser pensada na Europa assim que o padrão GSM $(2 \mathrm{G})$ inicia suas operações nos primeiros anos da década de 1990. O instituto europeu que regula os padrões de telecomunicações (ETSI) começa o trabalho de fundação de bases daquilo que viria a ser chamado sistema UMTS (Universal Mobile Telecommunications System). 
Já no final da década, em 1998, é criada uma parceria denominada 3GPP (3rd Generation Partnership Project), reunindo corporações para padronização das telecomunicações que atuam em cinco diferentes regiões do mundo (Europa, América do Norte, China, Japão c Coréia do Sul) c cujo esforço conjunto segue na direção de definir padrões globais para os sistemas $3 \mathrm{G}$.

A rigor, o UMTS ć uma nova rede que funciona de forma distinta da precedente e que irá aproveitar apenas uma parte de sua infra-estrutura, de forma que ambas possam operar em conjunto. A rede UMTS iniciou seu funcionamento com uma tecnologia de interface aérea denominada WCDMA (Acesso Múltiplo por Divisão de Código em Banda Larga). Essa tecnologia, em contrapartida às anteriores, não define um canal físico para uma chamada de voz ou para transferência de dados; cla atribui códigos às chamadas de voz e às ligações de dados e usa uma técnica de "espalhamento" (spread) do sinal por toda banda de frequências disponível. A estação móvel do destinatário sabe o código apropriado para sua ligação e descarta automaticamente quaisquer dados que não levem esse código consigo. Tal método liberta espaço na rede e, mais uma vez, aumenta sua capacidade com relação ao fluxo de informações. O ritmo de inovações e incrementos é acelerado e segue sempre nessa mesma direção. Aliás, mesmo o padrão UMTS/3G já sofreu atualizações, sendo a principal delas para otimizar a capacidade da rede $\mathrm{em}$ transmitir dados na direção das estações móveis (downlink), promovendo um fluxo desigual entre "subida" e "descida" de dados e privilegiando assim o recebimento de dados por parte dos usuários.

A tecnologia $4 \mathrm{G}$ já está sendo pensada e foi batizada com o nome "Evolução de Longo Prazo" (LTE, cm inglês). Sabe-se que esta evolução deverá basear-se no padrão OFDMA (Ort/sogonal Frequency Division Multiple Access) que deverá oferecer uma taxa de dados de $100 \mathrm{Mbit} / \mathrm{s}$ no downlink, $\mathrm{e}$ poderá iniciar suas operações em 2010.

Recapitulando, vemos que desde a primeira atualização no padrão GSM (2G) se impõe uma nova prioridade ao desenvolvimento da rede que é de aumentar sua capacidade de fluxo de dados. Se a evolução sofrida pela radiotelefonia que deu origem à telefonia celular pretendia aumentar a área de 
cobertura da rede bem como seu número de usuários e, logo em seguida, a evolução entre a primeira e a segunda geração também tinha o número de usuários como sua principal motivação, a partir daí, com a digitalização do sinal, toda evolução teve como seu objetivo alargar a capacidade dos dados em movimentarem-se pela rede. Noutras palavras, quero indicar que de início era preciso firmar bases para a articulação entre comunicação e movimento construindo os mecanismos de mobilidade territorial dos celulares, possibilitando inclusive o crescimento irrestrito de suas fronteiras e de seu contingente. Satisfeitos os primeiros objetivos, a orientação muda e o que passa a ditar o ritmo das mudanças é a tentativa de aumentar o fluxo de dados da rede e, com isso, introduzir novos pacotes de serviço e fontes de receita.

A introdução do padrão GPRS dentro do sistema GSM marca essa virada. A partir de técnicas de otimização c divisão do tempo, de modulação ou "compressão" do sinal, e do próprio "espalhamento" da informação pela interface aérea, a tecnologia celular acelera a mobilidade dos dados em transitar pela rede. Para se ter uma ideia, tomando a capacidade ideal de transmissão de dados do padrão GPRS (171,2 Kbit/s), c fazendo seu enfrentamento com a capacidade que está sendo projetada para o vindouro sistema 4G (100 Mbit/s), verificamos que o fluxo potencial de informação será acelerado em 600 vezes.

Voltando à questão que nós fizemos um pouco mais atrás, a respeito da performance do iPhone 3G, que executa uma determinada tarefa em três vezes menos tempo que a versão anterior. Podemos dizer, à luz do que vimos, que não se trata necessariamente de ganho de tempo, mas, essencialmente, de ganho de informação. A melhora na performance do objeto, para além de economizar tempo e tornar a tarefa mais ágil, indica crescimento na sua capacidade de transmissão e recepção de dados. Este fluxo, ao que parece, é o que confere uma forma específica de mobilidade ao celular: a mobilidade com relação à sua forma. 


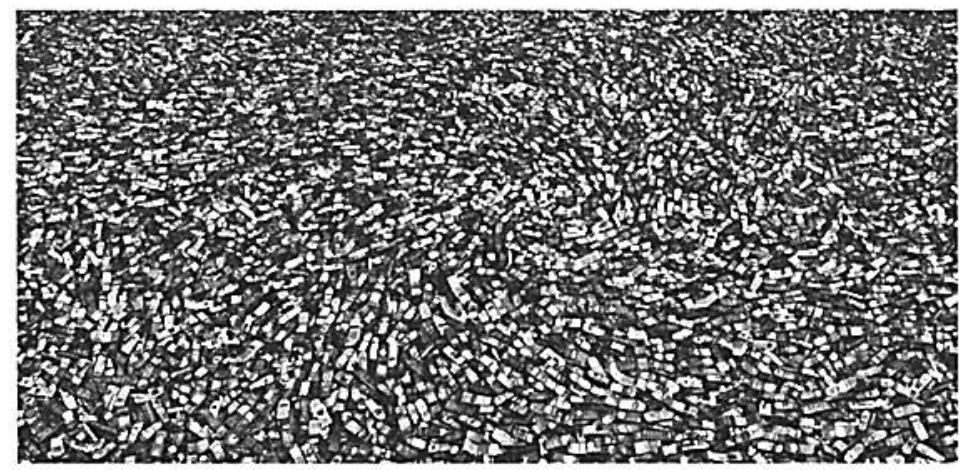

Foto de Chris Jordan, "Cell phones \# 2, Atlanta 2005" 44 x 90"

\section{FLUXO E MOBILIDADE}

A mobilidade dos dados, seu fluxo rápido e acelerado pelo sistema, torna o aparelho celular um objeto indefinido, cm constante mutação, também ele móvel, instável, centro do processo de convergência tecnológica. A mobilidade, neste caso, se manifesta em dois 'corpos' do sistema. O primeiro corpo é a informação, o fluxo de dados, de códigos binários que correm de maneira acelerada pelo sistema de telefonia celular em conexão com outros sistemas comunicativos de Internet, telefonia fixa e televisão (agora digital). $\mathrm{O}$ aumento do fluxo impulsiona o desenvolvimento da microeletrônica aplicada aos celulares - segundo corpo -, já que precisa aumentar sua capacidade de cálculo, suportar e executar novas mídias, realizar tarefas simultâneas, enfim, dar conta do montante de dados que irrompe em seu destino. Isso faz dele um objeto informe, que possui facilidade em modificar-se ou variar de estado e que agrega novas funções, tarefas e configurações.

Podemos dizer que o aparelho celular é informado pelo fluxo de dados do sistema celular. Aqui, informar recupera o sentido de dar forma(s) a algo. O terminal móvel, portanto, se configura de acordo com o fluxo de dados $\mathrm{c}$ que recebe, i.e., é informado pelo fluxo de informações. Se a evolução dos sistemas celulares aponta na direção de aumentar a corrente de dados em 
continuada aceleração, a forma adquirida pelo terminal móvel, pelo aparelho celular, é sempre contingente, temporária, indefinida, e tende também a modificar-se continuamente de forma acelerada. O percurso contrário também se verifica: o lançamento de terminais móveis com maior capacidade de cálculo e compilação de dados impulsiona a modernização das redes, embora isso tenha sido tocado aqui apenas nas entrelinhas.

A figura que se vê é de uma espiral de auto-reforço que aponta sempre na direção do aumento da capacidade de fluxo da rede, e da queda do tempo de vida útil de cada um dos modelos de aparelho. Nessa dinâmica, os usuários estão incluídos não só como receptores de dados, mas também como produtores. Seu envolvimento intenso enviando fotos, vídeos, navegando na Internet $\mathrm{c}$ inventando novos usos para o objeto, engrossa o caldo do fluxo que, por sua vez, dá ensejo a novos aparelhos que, em resultado, apresentam novas possibilidades de captura do usuário que termina por se envolver de maneira ainda mais intensa com o objeto, turbinando o movimento da espiral.

Replicando a cstratégia de Levinson (2004) que na citação no início desse artigo brincava com os significados da palavra cell, podemos dizer que aquilo que é mobile reúne em si propriedades do que é móvel. Na língua portuguesa, esse é um termo que se refere a qualquer objeto que tenha facilidade em mover-se ou ser movido, mas no sentido figurado pode também se referir a algo inconstante, volúvel, que tem facilidade em modificar-se ou variar de estado. Ao que parece, essa designação vem bem ao caso, porque reflete não só a propriedade do celular em conciliar comunicação e movimento, transitando dentro das áreas de acesso ao ciberespaço, como também resume sua propriedade de ser indefinido, informe, a frequência com que passa de um estado a outro agregando funções, e tendo seu desigh modificado. Nomeálo como mobile me parece coerente antes de tudo porque não é uma definição estática, na verdade, ela subentende que o objeto é seu próprio processo de desenvolvimento, seu devir. É sempre a possibilidade de tornar-se outra coisa, é a certeza de mutação c adaptação. É potência. 
ABSTRACT: Nowadays the term "mobility" is recurrent in our vocabulary. Used in different ways, this term became a very celebrated quality, desired and positive, largely due to its association with the mobile communication technologies, particularly, the cellular networks technology. The present paper intends to show what forms of mobility are produced by this technology, exploiting its operation's logic and its cvolutionary linc. 'Therefore the purpose here is to explore the mobile communication network's technicalitics and check the forms of mobility as manifested through their mobile devices (cell phones): these objects that articulate communication and movement and that are moreover in a continuous process of change and adaptation.

KEYWORDS: mobility, technology, communication, mobile phones, convergence.

\section{REFERÊNCIAS BIBLIOGRÁFICAS}

AGAR, Jon. Constant Touch: a global bistory of the mobile plone. Cambridge: Icon Books, 2003.

LEVINSON, Paul. Cellphone: The story of the world's most mobile medium, and how it bas transformed everything! New York, NY: Palgrave Macmillan, 2004.

RIVIĖRE, Carole Anne. Télepbone Móbile et Pbotograpbie: les nouvelles formes de sociabilités visuelles an quotidien. Sociétés, Paris, nº91(1), 2006, pp. 119-134.

TAYLOR, Alex S; VINCENT, Jeane. An SMS History. In: Mobile World: past, present, and future. HAMILL, Lynne; LASEN, Amparo (orgs). Ed. Springer, 2005. 